\title{
Penerapan Model Pembelajaran Problem Based Learning untuk Meningkatkan Motivasi Belajar IPA
}

\author{
I Gusti Ketut Yasmini ${ }^{1 *}$
}

SD N 3 Banyuasri, Singaraja, Indonesia

\author{
A R T I C L E I N F O \\ Article history: \\ Received 02 February \\ 2021 \\ Received in revised form \\ 30 March 2021 \\ Accepted 07 April 2021 \\ Available online 02 May \\ 2021

\section{Kata Kunci:} \\ Motivasi Belajar IPA, PBL \\ Keywords: \\ Science Learning \\ Motivation, $P B L$
}

\begin{abstract}
A B S T R A K
Penerapan model pembelajaran yang kurang efektif dimasa pandemi covid 19 menyebabkan motivasi belajar siswa menjadi berkurang, sehingga diperlukan model pembelajaran yang kreatif dan inovatif. Adapun tujuan dari diadakannya penelitian ini adalah untuk menganalisis peningkatan motivasi belajar IPA siswa kelas IV semester I setelah diterapkannya model pembelajaran Problem Based Learning (PBL). Penelitian ini adalah penelitian tindakan kelas. Subjek penelitian ini adalah siswa kelas IV dengan jumlah keseluruhan 17 siswa. Sedangkan objek penelitian ini adalah motivasi belajar IPA siswa setelah mengikuti pembelajaran dengan menerapkan model pembelajaran PBL. Metode pengumpulan data yang digunakan untuk mengumpulkan data motivasi belajar IPA siswa adalah metode kuesioner. Teknik analisis data yang digunakan dalam penelitian tindakan kelas ini adalah teknik analisis deskriptif kuantitatif. Hasil penelitian ini menunjukkan bahwa, rata-rata yang didapat pada siklus I sebesar 106,82 dan meningkat pada siklus II
\end{abstract} menjadi 120,29 , serta ketuntasan klasikal pada siklus I sebesar $82,35 \%$ dan meningkat pada siklus II menjadi $100 \%$. Simpulan penelitian ini adalah penerapan model pembelajaran $P B L$ dapat meningkatkan motivasi belajar IPA siswa Kelas IV Semester I. Implikasi penelitian ini dari penerapan model pembelajaran $P B L$ ini mendorong siswa dapat berfikir kreatif, imajinatif, mengenalkan gagasan baru, serta mendorong siswa untuk memperoleh kepercayaan diri.

\section{A B S T R A K}

The application of ineffective learning models during the COVID-19 pandemic caused student learning motivation to decrease, so that creative and innovative learning models are needed. The purpose of holding this research is to analyze the increase in motivation to learn science class IV semester I students after the implementation of the Problem Based Learning (PBL) learning model. This research is a classroom action research. The subjects of this study were students of grade $I V$ with a total of 17 students. While the object of this research is students' motivation to learn science after participating in learning by applying the PBL learning model. The data collection method used to collect students' science learning motivation data was a questionnaire method. The data analysis technique used in this classroom action research is quantitative descriptive analysis technique. The results of this study indicate that, the average obtained in the first cycle was 106.82 and increased in the second cycle to 120.29, and the classical completeness in the first cycle was $82.35 \%$ and increased in the second cycle to $100 \%$. The conclusion of this research is that the application of the PBL learning model can increase the motivation to learn Science of Class IV Semester I students. The implication of this research is that the application of the PBL learning model encourages students to think creatively, imaginatively, introduce new ideas, and encourage students to gain self-confidence.

\section{Pendahuluan}

Pendidikan merupakan hal yang sangat penting dalam menunjang sumber daya manusia yang ada dan hendaknya sudah diberikan sejak jenjang sekolah dasar (Kurniaman \& Noviana, 2017; Kurniasari, 2017; Nuryana \& Sahrir, 2020). Menurut (Divayana et al., 2016; Mulyadin, 2016; Susilo et al., 2018) bahwa 
pendidikan merupakan suatu kegiatan yang berguna untuk mengoptimalkan potensi, kecakapan dan karakteristik pribadi peserta didik. Kegiatan pendidikan ini diarahkan untuk mencapai suatu tujuan tertentu yang disebut dengan tujuan pendidikan.

Untuk mencapai tujuan pendidikan yang ada, seorang guru dituntut agar dapat memiliki pemikiran yang kreatif dan inovatif dalam memberikan pembelajaran kepada siswa sehingga pembelajaran menjadi menarik dan agar dapat mencapai tujuan-tujuan pembelajaran yang diharapkan. Pembelajaran yang menarik adalah pembelajaran yang dikonsepkan sedemikian rupa oleh guru kepada siswa dengan mengaitkan konteks nyata dalam kehidupan siswa sehingga siswa mampu memahami pembelajaran dan juga dapat memaknai nilai yang ada (Herzon et al., 2018; Maryatun \& Metro, 2017; Ramlawati et al., 2017). Pembelajaran seperti ini hendaknya mampu menghantarkan siswa dalam tujuan pembelajaran yang diharapkan sesuai dengan mata pelajaran yang diberikan.

Salah satu mata pelajaran yang diberikan kepada siswa pada jenjang sekolah dasar adalah pembelajaran Ilmu Pengetahuan Alam (IPA). Pembelajaran Ilmu pengetahuan Alam, terutama di tingkat SD hendaknya mengacu pada tingkat perkembangan siswa pada masa itu, yaitu tahap operasional konkret dan operasional formal (Cahyadi, 2016; Gunarta, 2019; Novita sari, 2018). Belajar akan menjadi efektif bila kegiatan belajar sesuai dengan tingkat perkembangan intelektual pebelajar, dan tidak ada belajar tanpa perbuatan. Hal ini disebabkan perkembangan intelektual siswa dan emosinya dipengaruhi langsung oleh keterlibatannya secara fisik dan mental dengan lingkungannya. Oleh karena itu pembelajaran Ilmu Pengetahuan Alam di pendidikan dasar, hendaknya mengupayakan pembelajaran melalui aktivitas konkret, dengan menghadirkan fenomena alam dalam setiap pembelajaran. Fenomena alam dalam proses pembelajaran identik dengan lingkungan yang digunakan sebagai sumber belajar untuk memahami materi-materi yang erat kaitannya dengan kehidupan sehari-hari (Karlina et al., 2017; Nikmatillah, 2018; Wardani et al., 2015).

Namun pada kenyataanya di kelas IV SD N 3 Banyuasri Tahun Pelajaran 2020/2021 dalam pembelajaran IPA terlihat bahwa motivasi belajar siswa rendah. Hal itu dikarenakan pada masa pandemi Covid 19, proses pembelajaran yang diberikan guru dilakukan secara dalam jaringan (daring). Proses pembelajaran dalam jaringan yang diberikan guru cenderung monoton hanya memberikan tugas kepada siswa, dan setelah siswa menjawab tugas tersebut, siswa mengirimkan jawaban tugasnya kepada guru. Proses ini terus berulang setiap hari, dan tugas yang diberikan guru cenderung hanya menuntut aspek kognitif siswa saja, sehingga lama-kelamaan siswa merasa jenuh dalam mengerjakan tugas guru. Hal ini terbukti dari banyaknya siswa yang lambat mengirimkan jawaban tugas yang diberikan guru, dan tugas yang dibuat siswa hanya sekedar menjawab pertanyaan saja.

Salah satu model pembelajaran yang dapat diterapkan untuk mengatasi permasalahan di atas adalah model pembelajaran problem based learning. Model pembelajaran prolem based learning adalah salah satu model pembelajaran yang sangat ideal diterapkan dalam pembelajaran IPA (Han \& Rosli, 2016; Ratnawati et al., 2020; Wajdi, 2017). Topik IPA yang cukup luas dan desain tugas-tugas atau sub-sub topik yang mengarah pada kegiatan metode ilmiah, diharapkan siswa dan kelompoknya dapat saling memberi kontribusi berdasarkan pengalaman sehari-hari (Fitri et al., 2020; Istiandaru et al., 2015; Sumarni et al., 2016).

Problem Based Learning merupakan pembelajaran berbasis masalah memberikan kesempatan kepada siswa untuk mengungkapkan gagasan secara eksplisit, memberi pengalaman yang berhubungan dengan gagasan yang telah dimiliki siswa (Adawiyah, 2018; Priyanti et al., 2016; Yuwono \& Syaifuddin, 2017). Sehingga siswa terdorong untuk membedakan dan memadukan gagasan tentang fenomena yang menantang. Model pembelajaran problem based learning memiliki kelebihan untuk mendorong siswa dapat berfikir kreatif, imajinatif, refleksi, tentang model dan teori, mengenalkan gagasan-gagasan pada saat yang tepat, mencoba gagasan baru, mendorong siswa untuk memperoleh kepercayaan diri (Ariyanti, 2017; Christiana et al., 2014; Desnylasari et al., 2016).

Penelitian ini didukung dengan beberapa penelitian yang relevan yaitu, pertama penelitian yang dilakukan oleh (Herzon et al., 2018), yang memperoleh hasil penelitian bahwa model pembelajaran problem based learning berpengaruh untuk meningkatkan keterampilan berpikir kritis siswa. Kedua, penelitian yang dilakukan oleh (Defiyanti \& Sumarni, 2019), yang memperoleh hasil penelitian bahwa penerapan $P B L$ berbantuan lembar kerja siswa bermuatan etnosains berpengaruh terhadap kemampuan berpikir kritis siswa dan mendapatkan respon positif dari siswa. Ketiga, penelitian yang dilakukan oleh (Abdurrozak \& Jayadinata, 2016), yang memperoleh hasil penelitian bahwa pembelajaran IPA dengan menerapkan model pemblajaran PBL dapat meningkatkan kemampuan siswa untuk berpikir kreatif.

Tujuan dari diadakannya penelitian ini adalah untuk menganalisis peningkatan motivasi belajar IPA siswa kelas IV semester I di SDN 3 Banyuasri Kecamatan Buleleng Kabupaten Buleleng tahun pelajaran 2020/2021 setelah diterapkannya model pembelajaran Problem Based Learning. 


\section{Metode}

Penelitian ini termasuk kedalam jenis penelitian tindakan kelas (PTK) yang terdiri dari empat tahapan pada satu siklus penelitian. Keempat tahapan tersebut terdiri dari planing, action, observation/evaluation, dan reflection. Sedangkan pelaksanaan penelitian ini dilakukan dalam dua siklus. Penelitian ini dilaksanakan di SDN 3 Banyuasri semester I tahun pelajaran 2020/2021. Penelitian ini dilaksanakan dari bulan Agustus sampai Nopember 2020.

Subjek penelitian ini adalah siswa kelas IV semester I SD N 3 Banyuasri tahun pelajaran 2020/2021 dengan jumlah keseluruhan 17 siswa. Adapun objek penelitian ini adalah motivasi belajar IPA siswa setelah mengikuti pembelajaran dengan menerapkan model pembelajaran Problem Based Learning $(P B L)$.

Data yang dikumpulkan oleh peneliti adalah data yang mengenai motivasi belajar IPA siswa. Adapun metode yang dapat dilakukan untuk mengumpulkan data motivasi belajar IPA siswa adalah metode kuesioner. Metode kuesioner merupakan suatu metode pengumpulan data yang bertujuan untuk memperoleh jawaban dari responden dengan cara mengajukan lembar pertanyaan ataupun pernyataanpernyataan dalam bentuk jawaban secara tertulis pula (Hazmiwati, 2018; Suratno, 2013; Yuliarni et al., 2013).

Pada penelitian ini, teknik analisis data yang digunakan dalam penelitian tindakan kelas ini adalah dengan menggunakan teknik analisis deskriptif kuantitatif. Indikator keberhasilan pelaksanaan ini, berpedoman pada kriteria yaitu rata-rata motivasi belajar IPA siswa minimal pada kategori tinggi, dan ketuntasan klasikal sebesar 85\%.

\section{Hasil dan Pembahasan}

Dalam proses belajar mengajar, guru hendaknya menggunakan model pembelajaran yang bervariasi agar siswa tidak jenuh belajar. Salah satunya model PBL yang dapat merangsang kemampuan siswa dalam berpikir tingkat tinggi. Hal ini juga diungkapkan oleh (Herzon et al., 2018; Maryatun \& Metro, 2017; Rerung et al., 2017), bahwa PBL merupakan salah satu model yang dapat digunakan meningkatkan hasil belajar (kognitif, afektif, dan psikomotor) dan kemampuan berpikir tingkat tinggi siswa. PBL merupakan salah satu model pembelajaran yang menyajikan masalah sebagai rangsangan (stimulus) untuk belajar. Penyajian situasi masalah yang autentik dan bermakna kepada siswa dapat memberikan kemudahan kepada siswa untuk melakukan penyelidikan dan inkuiri.

Menurut (Istiandaru et al., 2015; Ratnawati et al., 2020; Wajdi, 2017) model pembelajaran PBL adalah suatu model belajar yang menghadapkan siswa dengan masalah-masalah nyata yang memberi rangsangan untuk belajar. Dalam hal ini siswa diberikan masalah yang struktur sebelum mereka diberikan materi pelajaran agar siswa mampu menemukan sendiri konsep dalam pembelajaran. Model pembelajaran ini sangat cocok diterapkan pada mata pelajaran IPA, karena pada pembelajaran IPA siswa dituntut aktif untuk berpikir kreatif, imajinatif dan yang lainnya. Kreativitas siswa sangat dituntut karena pada pembelajaran IPA materinya tidak bisa hanya dihafal, namun juga dipraktekkan atau melakukan praktikum.

Berdasarkan penelitian yang telah dilakukan dengan menerapkan Model pembelajaran Problem Based Learning, didapatkan bahwa rerata Motivasi Belajar IPA siswa pada siklus I berada pada kategori tinggi dengan ketuntasan klasikal sebesar 82,35\%. Hasil ini menunjukkan bahwa indikator keberhasilan penelitian belum tercapai secara maksimal, dikarenakan ketuntasan klasikal siswa belum mencapai 85\%.

Belum tercapainya ketuntasan klasikal siswa disebabkan karena ada beberapa siswa yang kurang aktif dalam mencari pemecahan permasalahan yang dihadapinya saat proses pembelajaran. Terutama dalam hal membaca materi atau buku, padahal beberapa permasalahan ada jawabannya di materi buku yang mereka miliki. Rendahnya antusias siswa dalam membaca materi di buku, mengindikasikan motivasi belajar siswa belum optimal.

Berdasarkan penelitian yang sudah dilaksanakan pada siklus II, terlihat bahwa pembelajaran pada siklus II sudah berjalan lebih baik dari siklus I. Hal tersebut terbukti dari peningkatan rata-rata motivasi belajar siswa yang meningkat menjadi sangat tinggi dan ketuntasan klasikal siswa yang mencapai $100 \%$. Dan ini berarti bahwa indikator keberhasilan dalam penelitian ini sudah tercapai dengan maksimal.

Pada pembelajaran siklus II, siswa sudah mulai terbiasa membaca dari berbagai macam sumber, sudah terbiasa mencari point-point dari apa yang mereka pelajari, sudah terbiasa mencatat point-point dari materi pembelajaran, dan sumber belajar yang dimiliki siswa sudah lebih beragam. Hal ini menyebabkan siswa lebih mudah untuk memecahkan permasalahan-permasalahan yang diberikan atau dihadapinya saat proses pembelajaran. 
Secara keseluruhan kendala yang dihadapi pada siklus II tidak terlalu nampak, namun hanya perlu pembiasaan yang lebih agar siswa mau membaca dari berbagai macam sumber sehingga wawasan siswa menjadi luas. Untuk lebih jelasnya, peningkatan rata-rata dan ketuntasan klasikal siswa dari siklus I sampai siklus II dapat dilihat pada Gambar 1.

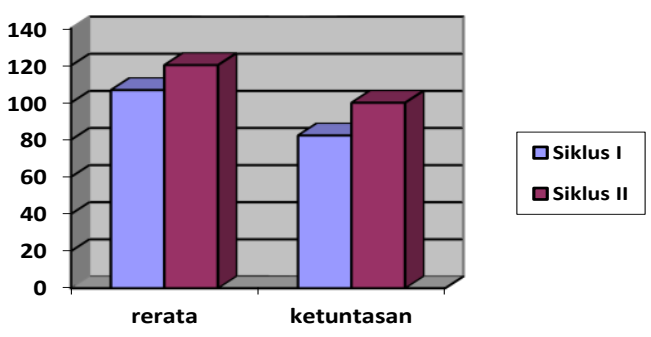

Gambar 1. Peningkatan Rata-Rata Dan Ketuntasan Klasikal Siswa dari Siklus I Sampai Siklus II

Berdasarkan Gambar 1 diperoleh hasil rata-rata yang didapat pada siklus I sebesar 106,82 dan meningkat pada siklus II menjadi 120,29, serta ketuntasan klasikal pada siklus I sebesar 82,35\% dan meningkat pada siklus II menjadi 100\%. Peningkatan ini dapat terjadi karena penerapan model problem based learning memiliki kelebihan antara lain siswa lebih aktif dalam pembelajaran, kemampuan siswa lebih terasah, siswa dapat melatih kerjasama dalam kelompok, menciptakan semangat kompetisi antar kelompok, melatih siswa lebih kreatif, imajinatif, serta mendorong siswa untuk memperoleh kepercayaan diri (Istiandaru et al., 2015; Ratnawati et al., 2020; Wajdi, 2017).

Problem Based Learning merupakan pembelajaran berbasis masalah memberikan kesempatan kepada siswa untuk mengungkapkan gagasan secara eksplisit, memberi pengalaman yang berhubungan dengan gagasan yang telah dimiliki siswa (Adawiyah, 2018; Priyanti et al., 2016; Yuwono \& Syaifuddin, 2017). Sehingga siswa terdorong untuk membedakan dan memadukan gagasan tentang fenomena yang menantang. Model pembelajaran problem based learning memiliki kelebihan untuk mendorong siswa dapat berfikir kreatif, imajinatif, refleksi, tentang model dan teori, mengenalkan gagasan-gagasan pada saat yang tepat, mencoba gagasan baru, mendorong siswa untuk memperoleh kepercayaan diri (Ariyanti, 2017; Christiana et al., 2014; Desnylasari et al., 2016).

Penelitian ini didukung dengan beberapa penelitian yang relevan yaitu, pertama penelitian yang dilakukan oleh (Herzon et al., 2018), yang memperoleh hasil penelitian bahwa model pembelajaran problem based learning berpengaruh untuk meningkatkan keterampilan berpikir kritis siswa. Kedua, penelitian yang dilakukan oleh (Defiyanti \& Sumarni, 2019), yang memperoleh hasil penelitian bahwa penerapan $P B L$ berbantuan lembar kerja siswa bermuatan etnosains berpengaruh terhadap kemampuan berpikir kritis siswa dan mendapatkan respon positif dari siswa. Ketiga, penelitian yang dilakukan oleh (Abdurrozak \& Jayadinata, 2016), yang memperoleh hasil penelitian bahwa pembelajaran IPA dengan menerapkan model pemblajaran PBL dapat meningkatkan kemampuan siswa untuk berpikir kreatif.

Implikasi dari penerapan model pembelajaran problem based learning ini adalah mendorong siswa dapat berfikir kreatif, imajinatif, mengenalkan gagasan baru, serta mendorong siswa untuk memperoleh kepercayaan diri.

\section{Simpulan}

Berdasarkan hasil dan pembahasan penelitian yang telah didapatkan, maka disimpulkan bahwa penerapan model pembelajaran problem-based learning dapat meningkatkan motivasi belajar IPA siswa Siswa Kelas IV Semester I di SD N 3 Banyuasri Kecamatan Buleleng Kabupaten Buleleng Tahun Pelajaran 2020/2021. Implikasi dari penerapan model pembelajaran problem-based learning ini adalah mendorong siswa dapat berfikir kreatif, imajinatif, mengenalkan gagasan baru, serta mendorong siswa untuk memperoleh kepercayaan diri. 


\section{Daftar Rujukan}

Abdurrozak, R., \& Jayadinata, A. K. (2016). Pengaruh Model Problem Based Learning Terhadap Kemampuan Berpikir Kreatif Siswa. Jurnal Pena Ilmiah, 1(1), 871-880. https://doi.org/10.23819/pi.v1i1.3580.

Adawiyah, R. (2018). Implementasi Metode Problem Based Learning Pada Mata Pelajaran Al-Quran dan Hadist Untuk Meningkatkan Hasil Belajar Kognitif dan Penanaman Sikap Peduli Sosial Pada siswa MTs Negeri 1 Sidoarjo. PEDAGOGIA: Jurnal Pendidikan, 7(1), 61-67. https://doi.org/10.21070/pedagogia.v7i1.1604.

Ariyanti, M. (2017). Perbandingan keefektifan model project-based learning dan problem-based learning ditinjau dari ketercapaian tujuan pembelajaran. Jurnal Pendidikan Matematika Dan Sains, 5(1), 1 10. https://doi.org/https://doi.org/10.21831/jpms.v5i1.13469.

Cahyadi, M. I. W. (2016). Penerapan Model TGT Meningkatkan Penguasaan Kompetensi Pengetahuan IPA Siswa Kelas VB SD Negeri 8 Pemecutan. MIMBAR PGSD Undiksha, 4(1), 1-10. https://doi.org/10.23887/jjpgsd.v4i1.7521.

Christiana, P. P., Suniasih, N. W., \& Suadnyana, I. N. (2014). Pengaruh Model Problem Based Learning Berbasis Penilaian Proyek terhadap Kemampuan Berpikir Kritis IPA SD Gugus VIII Sukawati. EJournal Mimbar PGSD Universitas Pendidikan Ganesha, 2(1). https://doi.org/10.23887/jjpgsd.v2i1.2031.

Defiyanti, \& Sumarni, W. (2019). Analisis Kemampuan Berpikir Kritis Peserta Didik Pada Penerapan Problem Based Learning Berbantuan Lembar Kerja Peserta Didik Bermuatan Etnosains. Phenomenon, 09(2), 206-218. https://doi.org/10.21580/phen.2019.9.2.4200.

Desnylasari, E., Mulyani, S., \& Mulyani, B. (2016). Pengaruh Model Pembelajaran Project Based Learning Dan Problem Based Learning Pada Materi Termokimia Terhadap Prestasi Belajar Siswa Kelas Xi Sma Negeri 1 Karanganyar Tahun Pelajaran 2015/2016. Jurnal Pendidikan Kimia (JPK), 5(1), 134142. https://onesearch.id/Record/IOS509.article-7419/Details.

Divayana, D. G. H., Suyasa, P. W. A., \& Sugihartini, N. (2016). Pengembangan media pembelajaran berbasis web untuk matakuliah kurikulum dan pengajaran di jurusan pendidikan teknik informatika Universitas Pendidikan Ganesha. Jurnal Nasional Pendidikan Teknik Informatika (Janapati), 5(3), 149. https://doi.org/10.23887/janapati.v5i3.9922.

Fitri, M., Yuanita, P., \& Maimunah, M. (2020). Pengembangan Perangkat Pembelajaran Matematika Terintegrasi Keterampilan Abad 21 Melalui Penerapan Model Problem Based Learning (PBL). Jurnal Gantang, 5(1), 77-85. https://doi.org/10.31629/jg.v5i1.1609.

Gunarta, I. G. (2019). Pengaruh Model Pembelajaran TGT Berbantuan Media Question Card Terhadap Hasil Belajar IPA. Jurnal Pedagogi Dan Pembelajaran, 1(2), 112. https://doi.org/10.23887/jp2.v1i2.19338.

Han, S., \& Rosli, R. (2016). The Effect of Science, Technology , Engineering and Mathematics ( STEM ) Project Based Learning ( PBL ) on Students ' Achievement in Four Mathematics Topics. Journal of Turkish Science Education, 13, 3-29. https://doi.org/10.12973/tused.10168a.

Hazmiwati, H. (2018). Penerapan Model Pembelajaran Kooperatif Tipe STAD Untuk Meningkatkan Hasil Belajar IPA Siswa Kelas II Sekolah Dasar. Primary: Jurnal Pendidikan Guru Sekolah Dasar, 7(1), 178. https://doi.org/10.33578/jpfkip.v7i1.5359.

Herzon, H. H., Budijanto, \& Utomo, D. H. (2018). Pengaruh Problem-Based Learning (PBL) terhadap Keterampilan Berpikir Kritis. Jurnal Pendidikan: Teori, Penelitian, Dan Pengembangan, 3(1), 4246. http://journal.um.ac.id/index.php/jptpp/.

Istiandaru, A., Istihapsari, V., Wardono, \& Mulyono. (2015). Problem Based Learning (PBL) dengan Pendekatan Realistik-Saintifik dan Asesmen PISA untuk Meningkatkan Kemampuan Literasi Matematika. Edumatica, 5(1), 1-11. https://doi.org/10.22437/edumatica.v5i01.2670.

Karlina, C. F., Dharsana, I. K., \& Kusmariyatni, N. (2017). Pembelajaran Kooperatif Tipe (TSTS) Berbantuan Peta Pikiran Untuk Meningkatkan Hasil Belajar IPA Melalui Lesson Study. Mimbar PGSD Undiksha, 5(2), 1-12. https://doi.org/http://dx.doi.org/10.23887/jjpgsd.v5i2.10883.

Kurniaman, O., \& Noviana, E. (2017). Penerapan Kurikulum 2013 Dalam Meningkatkan Keterampilan, Sikap, Dan Pengetahuan. Primary: Jurnal Pendidikan Guru Sekolah Dasar, 6(2), 389. https://doi.org/10.33578/jpfkip.v6i2.4520.

Kurniasari, F. (2017). Implementasi Pendekatan Saintifik Pada Penugasan Aktivitas Di Buku Teks Bahasa 
Indonesia Kelas VII SMP Berdasarkan Kurikulum 2013. Jurnal Pendidikan Edutama, 4(1), 9-26. https://doi.org/10.30734/jpe.v4i1.44.

Maryatun, \& Metro, P. E. F. U. M. (2017). Pengaruh Penggunaan Model Problem Based Learning (PBL) Terhadap Hasil Belajar Ekonomi Siswa Kelas X Semester Genap Sma Pgri 1 Metro Tahun Pelajaran 2016/2017. Jurnal Pendidikan EKonomi, 5(1), 152-159. https://doi.org/10.24127/ja.v5i2.1225.

Mulyadin. (2016). Implementasi Kebijakan Pembelajaran Tematik Terpadu Kurikulum 2013 Di SDN Kauman 1 Malang Dan SD Muhammadiyah 1 Malang. Jurnal Edutama, 3(2), 31-48. https://doi.org/10.30734/jpe.v3i2.35.

Nikmatillah, N. (2018). Penggunaan Media Papan Persilangan dapat Meningkatkan Hasil Belajar IPA Materi Perkawinan Silang Mahluk Hidup untuk Siswa Kelas IX C SMP Negeri 7 Malang Tahun 2015/2016. Jurnal Bidang Pendidikan Dasar, 2(1), 1-8. https://doi.org/10.21067/jbpd.v2i1.2187.

Novita sari, D. (2018). Pengaruh Model Pembelajaran Scramble Berbantuan Permainan Crossword Fuzle terhadap Kompetensi Pengetahuan IPA. Jurnal Penelitian Dan Pengembangan Pendidikan, 2(1), 68-74. https://doi.org/10.23887/jppp.v2i1.15340.

Nuryana, N., \& Sahrir, D. C. (2020). Pelatihan Kurikulum 2013 Edisi Revisi 2018 bagi Guru di Yayasan Pendidikan Islam Al-Maunah. Jurnal Pengabdian Pada Masyarakat, 5(1), 1 - 10. https://doi.org/10.30653/002.202051.259.

Priyanti, A. E., Wiarta, I. W., \& Ardana, I. K. (2016). Pendekatan Saintifik Berbasis Problem Based Learning Berpengaruh terhadap Hasil Belajar Pengetahuan Matematika Siswa Kelas IV SD Gugus. Jurnal PGSD Universitas Pendidikan Ganesha, 4(1), 1-10. https://doi.org/10.23887/jjpgsd.v4i1.7169.

Ramlawati, Yunus, S. R., \& Insani, A. (2017). Pengaruh Model PBL (Problem Based Learning) terhadap Motivasi dan Hasil Belajar IPA Peserta Didik. Jurnal Sainsmat, 6(1), 1-14. https://ojs.unm.ac.id/sainsmat/article/view/6451

Ratnawati, D., Handayani, I., \& Hadi, W. (2020). Pengaruh Model Pembelajaran Pbl Berbantu Question Card Terhadap Kemampuan Berpikir Kritis Matematis Siswa SMP. Edumatica : Jurnal Pendidikan Matematika, 10(01), 44-51. https://doi.org/10.22437/edumatica.v10i01.7683.

Rerung, N., Sinon, I. L. ., \& Widyaningsih, S. W. (2017). Penerapan Model Pembelajaran Problem Based Learning (PBL) untuk Meningkatkan Hasil Belajar Peserta Didik SMA pada Materi Usaha dan Energi. Jurnal Ilmiah Pendidikan Fisika Al-Biruni, 6(1), 47-55. https://doi.org/10.24042/jpifalbiruni.v6i1.597.

Sumarni, W., Wardani, S., \& Gupitasari, D. N. (2016). Project Based Learning (PBL) To Improve Psychomotoric Skills : A Classroom Action Research. Jurnal Pendidikan IPA Indonesia, 5(2), 157163. https://doi.org/10.15294/jpii.v5i2.4402.

Suratno. (2013). Pengaruh Penerapan Metode STAD Terhadap Hasil Belajar Ekonomi Ditinjau Dari Minat Siswa Di SMA N 10 Batanghari. Jurnal Pendidikan Ekonomi Dinamika Pendidikan, 8(2), 111-122. https://doi.org/10.15294/dp.v8i2.3367.

Susilo, A., Pratiwi, Y., \& Sunoto, S. (2018). Relevansi Nilai Sosial dalam Antologi Puisi Malu Aku Jadi Orang Indonesia Karya Taufik Ismail dengan Muatan Isi Kurikulum 2013. Jurnal Pendidikan: Teori, Penelitian, Dan Pengembangan, 3(1). https://doi.org/10.17977/jptpp.v3i1.10375.

Wajdi, F. (2017). Implementasi Project Based Learning (PBL) Dan Penilaian Autentik Dalam Pembelajaran Drama Indonesia. Jurnal Pendidikan Bahasa Dan Sastra, 17(1), 81-97. https://doi.org/10.17509/bs_jpbsp.v17i1.6960..

Wardani, N. K. T. Y. P., Sulastri, M., \& Margunayasa, I. G. (2015). Pengaruh Model Heuristik Vee dengan Peta Pikiran terhadap Hasil Belajar IPA Siswa Kelas V SD. Mimbar PGSD Undiksha, 3(1). https://doi.org/10.23887/jjpgsd.v3i1.5749.

Yuliarni, E., Luawo, M. I. R., \& Karsih, K. (2013). Pengaruh Penerapan Model Cooperative Learning Tipe STAD (Student Teams Achievement Division) Dalam Layanan Bimbingan Klasikal Terhadap Keterampilan Belajar Siswa Dalam Membaca Dengan Teknik SQ3R (Studi Pre-Eksperimen Pada Siswa Kelas X-F Di SMAN 8 Bogor). Insight: Jurnal Bimbingan Konseling, 2(1), 25-31. https://doi.org/10.21009/INSIGHT.021.05.

Yuwono, M. R., \& Syaifuddin, M. W. (2017). Pengembangan problem based learning dengan assessment for learning berbantuan smartphone dalam pembelajaran matematika. Beta Jurnal Tadris Matematika, 10(2), 184-202. https://doi.org/10.20414/betajtm.v10i2.116. 